\title{
De novo transcriptome assembly and population genetic analyses of an important coastal shrub, Apocynum venetum $\mathrm{L}$
}

\author{
Na Yuan ${ }^{1 *}$, Mimi Li ${ }^{2}$ and Chunlin $\mathrm{Jia}^{3}$
}

\begin{abstract}
Background: Apocynum venetum $\mathrm{L}$. is an important medicinal plant that is mainly distributed in the coastal areas and northwest of China. In addition to its high medical and economic value, its adaptation to saline-alkali and coastal saline lands makes $A$. venetum an ideal candidate for use in vegetation restoration. To date, the study of $A$. venetum has been limited in the northwest region of China, little attention has been paid to the genetic diversity and population structure of $A$. venetum populations in the coastal region. Here, we performed transcriptome sequencing of total RNA from $A$. venetum leaves and developed efficient expressed sequence tag-simple sequence repeat (EST-SSR) markers for analyzing the genetic diversity and population structure of $A$. venetum in the coastal region.
\end{abstract}

Results: A total of 86,890 unigenes were generated after de novo assembly, and 68,751 of which were successfully annotated by searching against seven protein databases. Furthermore, 14,072 EST-SSR loci were detected and 10, 243 primer pairs were successfully designed from these loci. One hundred primer pairs were randomly selected and synthesized, twelve primer pairs were identified as highly polymorphic and further used for population genetic analysis. Population genetic analyses showed that $A$. venetum exhibited low level of genetic diversity (mean alleles per locus, $N_{A}=3.3$; mean expected heterozygosity, $H_{E}=0.342$ ) and moderate level of genetic differentiation among the populations (genetic differentiation index, $F_{\mathrm{ST}}=0.032-0.220$ ) in the coastal region. Although the contemporary (mean $m_{c}=0.056$ ) and historical (mean $m_{h}=0.106$ ) migration rates among the six $A$. venetum populations were moderate, a decreasing trend over the last few generations was detected. Bayesian structure analysis clustered six populations into two major groups, and genetic bottlenecks were found to have occurred in two populations (QG, $\mathrm{BH}$ ).

Conclusions: Using novel EST-SSR markers, we evaluated the genetic variation of A. venetum in the coastal region and determined conservation priorities based on these findings. The large dataset of unigenes and SSRs identified in our study, combining samples from a broader range, will support further research on the conservation and evolution of this important coastal plant and its related species.

Keywords: Apocynum venetum L., Transcriptome, EST-SSR marker, Population genetics, Coastal wetland

\footnotetext{
*Correspondence: thefuries@163.com

'Institute of Crop Germplasm and Biotechnology, Provincial Key Laboratory of Agrobiology, Jiangsu Academy of Agricultural Sciences, Nanjing, China Full list of author information is available at the end of the article
}

(c) The Author(s). 2020 Open Access This article is licensed under a Creative Commons Attribution 4.0 International License, which permits use, sharing, adaptation, distribution and reproduction in any medium or format, as long as you give appropriate credit to the original author(s) and the source, provide a link to the Creative Commons licence, and indicate if changes were made. The images or other third party material in this article are included in the article's Creative Commons licence, unless indicated otherwise in a credit line to the material. If material is not included in the article's Creative Commons licence and your intended use is not permitted by statutory regulation or exceeds the permitted use, you will need to obtain permission directly from the copyright holder. To view a copy of this licence, visit http://creativecommons.org/licenses/by/4.0/ The Creative Commons Public Domain Dedication waiver (http://creativecommons.org/publicdomain/zero/1.0/) applies to the data made available in this article, unless otherwise stated in a credit line to the data. 


\section{Background}

Coastal habitats, which are located in the transition zone between terrestrial ecosystems and marine ecosystems, are characterized by unique, complex ecosystems with high ecological value [1]. Their unique environmental features, including poor soil structure with low water infiltration and poor drainage, a high salt content and $\mathrm{PH}$ level, give rise to unique plant diversity and many specialist species [2]. However, due to the rapid urbanization process, coastal habitats have been particularly affected by both land transformation and mass tourism, leading to the severe disturbance and loss of natural habitats [3]. Many coastal plants are adapted to specific costal environmental conditions and are thus highly vulnerable to habitat destruction [4-6]. Therefore, there is an urgent need to evaluate and protect the irreplaceable, vulnerable biodiversity found in the coastal zones, especially in the face of continuing anthropogenic pressure.

The coastal area of Jiangsu Province accounts for one quarter of the total coastal area in China, which mainly falls within Yancheng City [7]. The coastline of Yancheng City's is $582 \mathrm{~km}$ long, and the beach area covers 6.83 million $\mathrm{hm}^{2}$, with an annual growth rate of 10,000 $\mathrm{hm}^{2}$ [7]. The Yancheng coastal region not only provides precious land resources, but is also an important wetland nature reserve. According to the plant surveys, there are 688 kinds of vascular plants belonging to 391 genera and 114 families in the Yancheng tidal flat wetland [8]. Multiple large-scale beach reclamation projects have been conducted in Yancheng city since 1949, and the natural habitats of this region have been significantly modified [7]. Many studies have shown that anthropogenic habitat alterations can affect both global biodiversity and genetic diversity, which jeopardizes the longterm survival of species and increases their risk of extinction [9-13]. There are many valuable plant resources, such as Limonium sinense (Girard) Kuntze, Apocynum venetum, Tamarix chinensis Lour., Tournefortia sibirica, and Salicornia europaea L. etc. in the Yancheng tidal flat, which are not only tolerant to salt stress but also present high medical and economic values [8]. Whether the genetic diversity and genetic structure of coastal plant populations have been affected by coastal habitat changes has seldom been evaluated.

Apocynum venetum $\mathrm{L}$. is a perennial shrub that is specifically distributed in the coastal region of Jiangsu Province. It has also been referred to as "Luobuma" since it was first discovered on the Luopu plains of Xinjiang Province in the 1950s [14]. A. venetum not only provides precious fiber and nectar resources but is also used as an important medicinal plant for treating hypertension and hyperlipidemia. Its high stress resistance to high salt contents and poor soils also contribute to its great ecological value. To date, studies of $A$. venetum have mainly focused on its medicinal effects and physiological characteristics such as photosynthesis and water absorption [15-17]. However, few studies have examined the genetic diversity and genetic structure of natural $A$. venetum populations. To better protect and utilize this important plant species in the Yancheng coastal region, there is an urgent need to evaluate the genetic diversity and population structure of natural $A$. venetum populations.

Simple sequence repeat (SSR) markers have been widely used in population genetic analysis and molecular marker-assisted breeding because of their high polymorphism, repeatability and codominant inheritance [18, 19]. A number of transcriptome analyses have been conducted on A. venetum [20-22], while SSR markers have not yet been developed and used to evaluate the genetic diversity of natural $A$. venetum populations yet. Using RAPD (Random Amplification Polymorphic DNA) and AFLP (Amplified Fragment Length Polymorphism) markers, researchers have detected moderate to high levels of genetic diversity in A. venetum populations from Xinjiang and Inner Mongolia regions [23, 24]. Except in the arid region, there has been no study that has evaluated the genetic diversity of $A$. venetum populations in the coastal regions. Therefore, in this study, we conducted comprehensive transcriptome sequencing of $A$. venetum from the coastal region of Jiangsu Province using the Illumina sequencing platform. After data assembly and annotation, we developed a set of novel EST-SSR markers from the unigenes. By using these informative markers, we successfully evaluated the genetic diversity, population structure and demographic changes in six populations across the natural distribution of $A$. venetum in the Yancheng coastal region. We expect that the genetic information identified in this study will facilitate the management and conservation of natural $A$. venetum populations in the future.

\section{Results}

Assembly of $A$. venetum transcriptome data from Illumina sequencing

Transcriptome sequencing generated 46,408,308 reads, totalling approximately $6.96 \mathrm{~Gb}$ for $A$. venetum in this study. After stringent quality filtering, 45,760,331 (98.6\%) high-quality reads were obtained, exhibiting 98.31\% Q20 bases and a GC value of 46.93\% (Table 1). A total of 86,890 unigenes were successfully assembled using the Trinity software, with a mean length of 1767 bp and an N50 of $2580 \mathrm{bp}$. Among all the assembled unigenes, 3119 of which (approximately $3.58 \%$ ) were less than $300 \mathrm{bp}$, and 14,657 unigenes $(16.85 \%)$ were longer than $3000 \mathrm{bp}$, whereas most of the unigenes $(69,204)$ (79.56\%) ranged from 300 to $3000 \mathrm{bp}$ (Additional file 1: Fig. S1A). The number of reads mapped to each unigene analysis revealed that 13,065 unigenes (about 47.90\%) 
Table 1 Sequencing, assembly, and annotation results of $A$. venetum transcriptome

\begin{tabular}{ll}
\hline Description & Number \\
\hline 1. Raw sequences and Assembly statistics & \\
High-quality reads & $45,760,331$ \\
Total nucleotides of high-quality reads (bp) & $16,326,427,500$ \\
Q20 percentage & $98.31 \%$ \\
GC percentage of high-quality reads & $46.93 \%$ \\
Number of unigenes & 86,980 \\
Range of unigenes length (bp) & $201-17,334$ \\
N50 length of unigenes (bp) & 2580 \\
2. Bioinformatics annotations of unigenes & \\
Gene annotated against NR(\%) & 63,975 (73.55) \\
Gene annotated against NT(\%) & 48,088 (55.28) \\
Gene annotated against KO(\%) & 28,505 (32.77) \\
Gene annotated against SwissProt(\%) & 53,436 (61.43) \\
Gene annotated against PFAM(\%) & 51,451 (59.15) \\
Gene annotated against GO(\%) & 51,733 (59.47) \\
Gene annotated against KOG(\%) & 23,428 (26.93) \\
Gene annotated against all Databases(\%) & 13,207 (15.18) \\
Gene annotated against at least one Database(\%) & 68,751 (79.04) \\
Gene Unannotated & 18,229 (20.96) \\
\hline
\end{tabular}

and 5506 unigenes (approximately 20.19\%) consist of more than 100 and 1000 reads each, respectively, only a few unigenes (3.3\%) were derived from less than 10 reads (Additional file 1: Fig. S1B).

\section{Functional annotation}

Using NCBI BLAST tools, all assembled unigenes were searched against $\mathrm{Nr}, \mathrm{Nt}$, SwissProt, Pfam, GO, KO and KOG databases for functional annotation. Among the 86,980 unigenes, the greatest number of matches were annotated in the $\mathrm{Nr}$ database (63,975 unigenes, $73.55 \%$ of all unigenes), followed by the Swiss-Prot $(53,436$, 61.43\%), GO (51,733, 59.47\%) and Pfam (51,451, 59.15\%) databases (Table 1). In total, 68,751 (79.04\%) unigenes exhibited homologous matches in at least one database and 13,207 (15.18\%) unigenes were annotated in all seven databases (Table 1).

\section{Functional classification by GO and KOG}

To further evaluate the functions of these unigenes, we used GO assignments to annotate and analyze each unigene. A total of 51,733 unigenes were assigned to 54 functional subgroups. Among the three ontology categories, the largest was biological process (47.6\%), followed by cellular component $(29.5 \%)$ and molecular function (22.9\%) (Fig. 1). In the biological process group, the most frequent category was cellular process
(22.04\%), followed by metabolic process (20.99\%). Cell (19.40\%) and cell part (19.40\%) were the most highly represented groups in the cellular component category. For the molecular function category, binding (45.49\%) and catalytic activity (38.16\%) accounted for the greatest proportions. Then we submitted all the assembled unigenes to the KOG database for further functional prediction and classification. Among the 25 KOG categories, posttranslational modification, protein turnover and chaperones consist the largest group (13.36\%), general function prediction only (12.71\%) and translation, ribosomal structure and biogenesis (10.60\%) also showed high percentages (Additional file 2: Fig. S2).

\section{Functional classifications by KEGG}

A total of 28,505 unigenes were assigned to 130 KEGG pathways that belonged to five categories, namely, metabolic pathways $(44.08 \%)$, genetic information processing (22.55\%), cellular processes (4.5\%), environmental information processing (3.25\%) and organismal systems (2.89\%) (Fig. 2). The majority of the unigene pathways were associated with translation (2847 unigenes), carbohydrate metabolism (2553 unigenes), folding, sorting and degradation (1941 unigenes).

\section{Development and characterization of SSR markers}

In this study, a total of 14,072 SSRs with motifs ranging from di- to hexanucleotides were identified from 86,980 unigenes. Among all the SSR types, dinucleotide repeats accounts for the major proportion (9399, 66.8\%), followed by trinucleotides $(4328,30.76 \%)$. Tetranucleotide $(210,1.49 \%)$, hexanucleotide $(93,0.66 \%)$ and pentanucleotide $(42,0.30 \%)$ repeats were very low-frequency types. The numbers of tandem repeats of these SSRs ranged from five to 36 , and the most abundant repeat unit was six $(3571,25.38 \%)$, followed by five tandem repeats $(2670,18.97 \%)$ and seven tandem repeats (1950, 13.86\%) (Table 2). Among the dinucleotide repeats, the most abundant motif type was AG/CT (34.50\%), followed by AT/AT (23.39\%) and AC/GT (8.66\%). Among the trinucleotide repeats, AAG/CTT (8.99\%) was the most frequent motif type, followed by AAT/ATT (6.07\%). The remaining motif types accounted for $18.4 \%$ of these repeats (Table 2 ).

Within the 14,072 SSRs, 10,243 primer pairs were successfully designed. We randomly selected 100 pairs from these primer pairs for amplification, and 35 were successfully amplified at expected sizes. Using twelve individuals from four $A$. venetum populations, these 35 primer pairs were applied to screen for polymorphism and twelve showed allelic polymorphism (Table 3). Using these 12 polymorphic EST-SSR markers, a total of 39 alleles were detected across the 103 samples from the six coastal $A$. venetum populations, with 2 to 5 alleles 


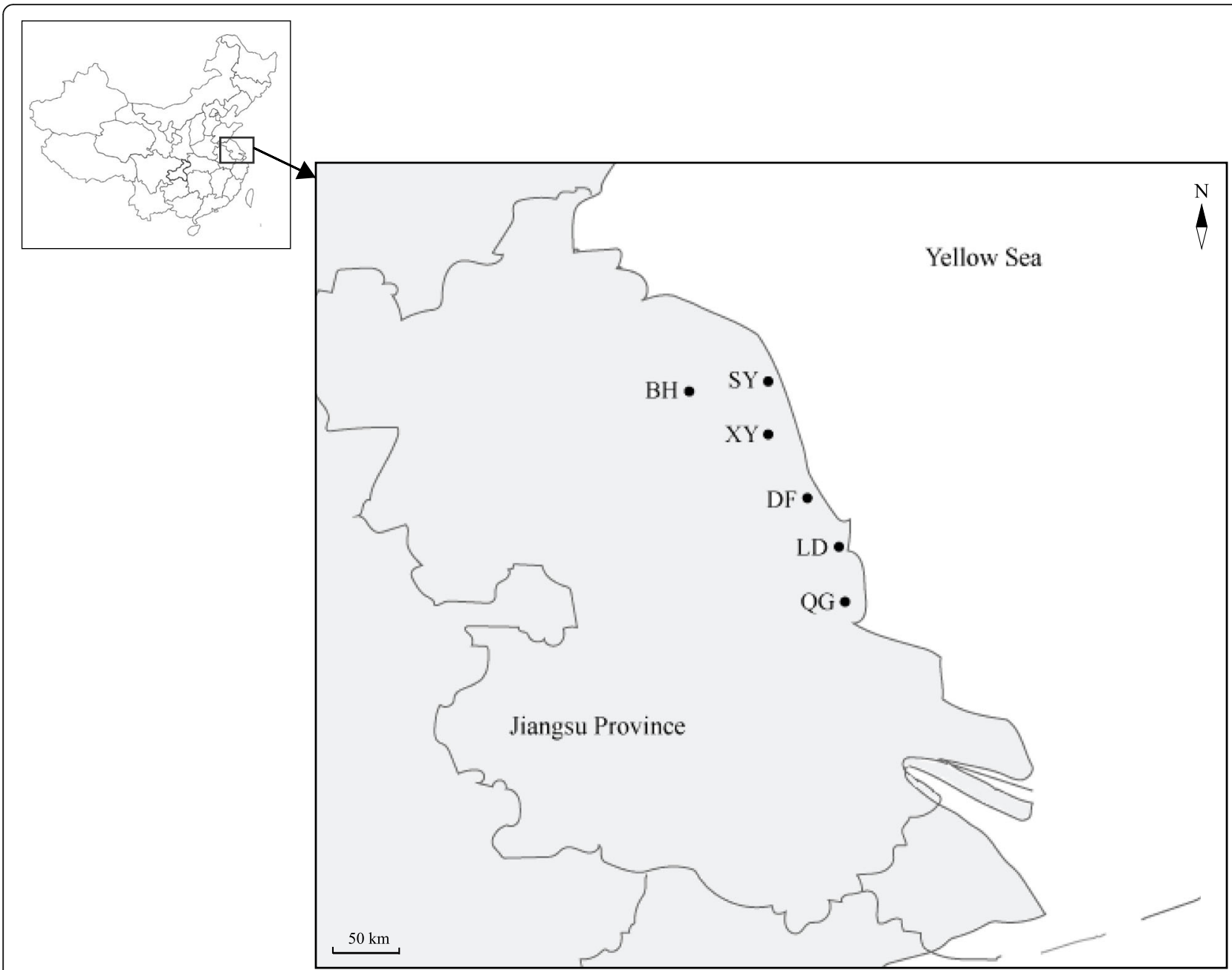

Fig. 1 Functional classification of Gene Ontology (GO) for assembled unigenes of A. venetum. A total of 51,733 unigenes were assigned into 54 functional groups of three $\mathrm{GO}$ categories

per locus. Using the Micro-Checker program, we found no evidence of null alleles and scoring errors in the dataset. Linkage disequilibrium analysis was performed between each pair of loci in each population. The results showed that 6 of 396 comparisons ( $A v 39$ and $A v 88$ in population LD; $A v 02$ and $A v 88$ in population XY; $A v 08$ and $A v 39, A v 08$ and $A v 63, A v 39$ and $A v 63, A v 39$ and $A v 75$ in population SY) were significant after Bonferroni correction $(P=0.00013)$. Given that there is no overlap between these six pairs of loci, we treated these 12 ESTSSR markers as independent loci in the following analyses. For all loci, the expected $\left(H_{\mathrm{E}}\right)$ and observed heterozygosities $\left(H_{\mathrm{O}}\right)$ ranged from 0.030 to 0.651 and from 0.030 to 0.653 , respectively. The polymorphism information content (PIC) was between 0.029 (Av55) and 0.575 (Av39), with an average of 0.297 (Table 3). Among 72 population-by-locus tests, departure from HWE was observed at locus $A v 02$ in the LD population, loci $A v 08$ and $A v 39$ in the QG population after sequential
Bonferroni correction $(P<0.004)$. Due to the significant $P$ values of these three loci that were only present in a single population, their departures from HWE most likely reflect population-specific rather than locusspecific problems.

\section{Analyses of population genetic diversity and structure}

For $A$. venetum, the average estimates of genetic diversity were generally low at the population level ( $\mathrm{AR}=2.34, H_{\mathrm{E}}=$ $\left.0.314, H_{\mathrm{O}}=0.350\right)$. Population $\mathrm{SY}$ showed the lowest level of genetic diversity $\left(\mathrm{AR}=1.96, H_{\mathrm{E}}=0.244\right.$, and $H_{\mathrm{O}}=$ $0.264)$ and population $\mathrm{XY}$ showed the highest $(\mathrm{AR}=2.52$, $H_{\mathrm{E}}=0.363$, and $\left.H_{\mathrm{O}}=0.410\right)$. The values of inbreeding $\left(F_{\mathrm{IS}}\right)$ ranged from -0.012 to -0.138 , with an average of 0.08 (Table 4). The $F_{\mathrm{ST}}$ values of population pairs ranged from 0.032 to 0.220 (Table 5), with an overall value of 0.101 , suggesting low to moderate levels of genetic differentiation across all the populations. Thirteen of the 15 
Gene Function Classification (GO)

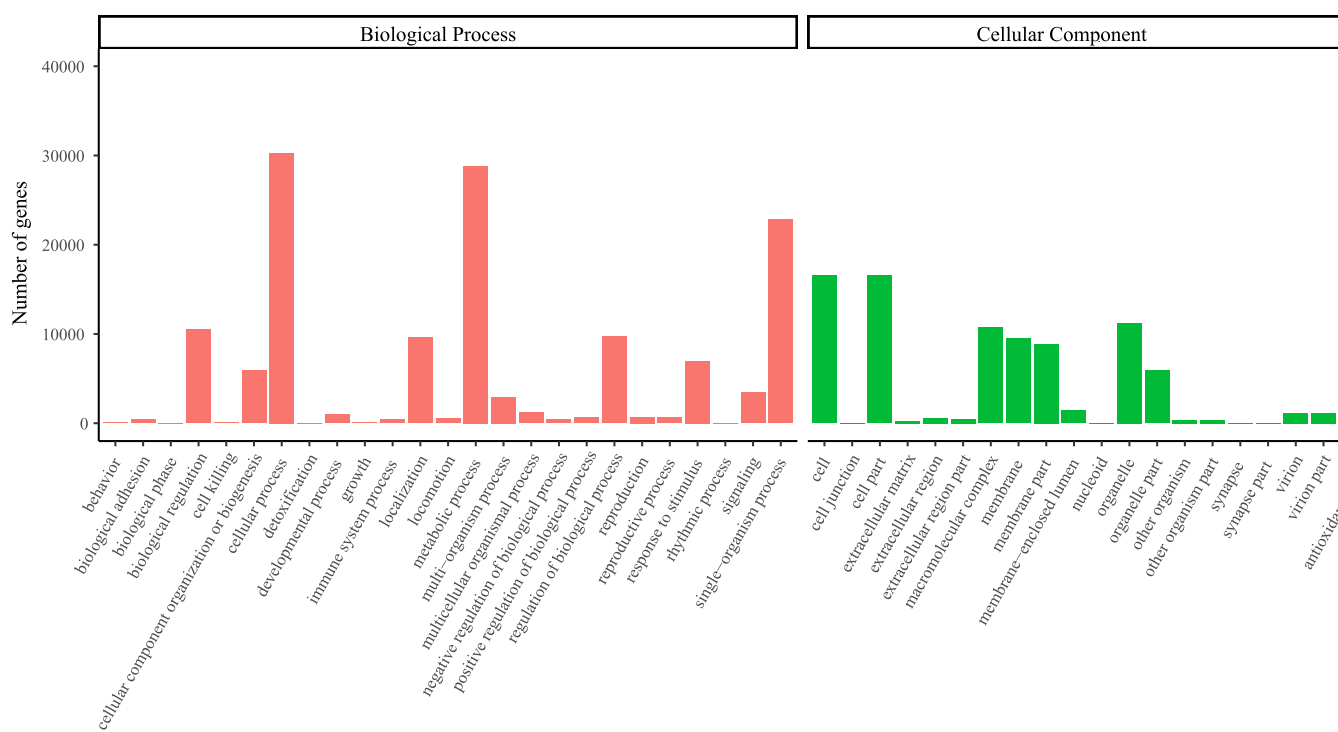

Fig. 2 Functional classification of unigenes of $A$. venetum in KOG category. Total of 23,428 unigenes were assigned into 25 functional groups

pairwise comparisons were significant after sequential Bonferroni correction (Table 5).

In the structure analysis, we used $\operatorname{LnP}(D)$ and $\Delta K$ statistics to determine the most likely value of population genetic cluster $K$. Because the $\operatorname{LnP}(D)$ increased progressively from $K=1$ to 6 , it was difficult to determine the true number of genetic clusters $(K)$. However, the $\Delta K$ statistic of Evanno et al. (2005) detected the highest peak at $K=2$ (Fig. 3a, b). Figure 3c exhibits the assignment of individuals to each cluster ('red' and 'blue' represent cluster I and cluster II, respectively) when $K=2$. The individuals that contain both colors represent the mixed origin of two gene pools. Cluster I and II were present at a high frequency (78 and $88 \%)(Q>0.80)$ in the DF and SY populations. For the QG and XY populations, nearly

Table 2 The distribution of $A$. venetum EST-SSRs based on the number of repeat units

\begin{tabular}{lllllll}
\hline Number of repeat unit & Di- & Tri- & Tetra- & Penta- & Hexa & Total \\
\hline 5 & 0 & 2395 & 174 & 27 & 74 & 2670 \\
6 & 2502 & 1008 & 28 & 14 & 19 & 3571 \\
7 & 1487 & 456 & 7 & 0 & 0 & 1950 \\
8 & 1151 & 209 & 1 & 1 & 0 & 1362 \\
9 & 944 & 118 & 0 & 0 & 0 & 1062 \\
10 & 639 & 91 & 0 & 0 & 0 & 730 \\
11 & 545 & 11 & 0 & 0 & 0 & 556 \\
12 & 448 & 13 & 0 & 0 & 0 & 461 \\
13 & 255 & 0 & 0 & 0 & 0 & 255 \\
14 & 345 & 12 & 0 & 0 & 0 & 357 \\
$\geq 15$ & 1083 & 15 & 0 & 0 & 0 & 1098 \\
\hline
\end{tabular}

half of the individuals were assigned to each cluster respectively. For the LD and $\mathrm{BH}$ populations, 10 to $50 \%$ of all local samples were assigned to each cluster, and the remaining 30\% consisted of mixed individuals. With increased values of $K(K=3)$, we observed that the SY population was assigned to a separated cluster III ('yellow') (Fig. 3c), suggesting the potential genetic differentiation of this population from the rest of the populations in the Yancheng region.

\section{Historical and contemporary gene flow}

The MigRATE-N results revealed that the mutation-scaled effective population size $(\Theta)$ for the six $A$. venetum populations ranged from 0.0342 to 0.0438 . Historical gene flow $\left(m_{\mathrm{h}}\right)$ that inferred from the mutation-scaled migration rate $(\mathrm{M})$ was highest from population LD to QG $\left(m_{\mathrm{h}}=0.169\right)$, and lowest from population LD to DF $\left(m_{\mathrm{h}}=0.041\right)$, with an average value of 0.106 across all the populations (Additional file 3: Table S1). Asymmetric gene flow was observed in two pairs of populations, with the predominant direction of gene flow occurring from population DF to $\mathrm{LD}$ and $\mathrm{XY}$ to $\mathrm{BH}$. Using BAYESAss software, we found that the six populations were largely composed of individuals (the average $72 \%$ ) that originated from within the same site, while approximately $6 \%$ of the individuals were exchanged with each other site (Additional file 3: Table S1). Although a moderate level of gene flow was detected among the six $A$. venetum populations, the Wilcoxon signed rank test indicated that the contemporary estimates (mean $m_{\mathrm{c}}=$ 0.056) were significantly lower than the historical estimates of migration rates (mean $m_{\mathrm{h}}=0.106, P<0.001$ ), 
Table 3 Characteristics of 12 compound microsatellite loci developed for A. venetum across all the samples. Shown for each locus are the locus name, the forward (F) and reverse (R) primer sequence, allele size, repeat motif, genetic characteristics and GenBank accession number

\begin{tabular}{|c|c|c|c|c|c|c|c|c|c|c|}
\hline Locus & Forward & Reverse & $\begin{array}{l}\text { Size } \\
(\mathrm{bp})\end{array}$ & SSR motif & $N_{\mathrm{A}}$ & $H_{0}$ & $H_{\mathrm{E}}$ & $\mathrm{PIC}$ & HWE & $\begin{array}{l}\text { GenBank accession } \\
\text { number }\end{array}$ \\
\hline Av02 & AAAAATGGGCAATGGTGGGC & $\begin{array}{l}\text { AGGCGTAGGTGAAGAGGA } \\
\text { GT }\end{array}$ & 224 & $(\mathrm{AT})_{11}$ & 5 & 0.515 & 0.511 & 0.462 & NS & MT737291 \\
\hline Av08 & AATCAGCCACCGAGTTACCG & $\begin{array}{l}\text { ACCTCCTGCAAGCTGAAT } \\
\text { CC }\end{array}$ & 220 & $(\mathrm{CAT})_{6}$ & 5 & 0.653 & 0.639 & 0.574 & NS & MT737292 \\
\hline Av13 & $\begin{array}{l}\text { ACGAGAAGTTGGAAACAG } \\
\text { ACCA }\end{array}$ & GTATTTGGTGTCTTCGGCGC & 269 & $(\mathrm{GT})_{6}$ & 3 & 0.050 & 0.049 & 0.048 & ND & MT737293 \\
\hline Av15 & ACTCGTTGGACATGATGTGCT & GGACCTTCTCATCAGCCTCG & 208 & $(\mathrm{CT})_{8}$ & 3 & 0.228 & 0.204 & 0.184 & ND & MT737294 \\
\hline$A v 21$ & AGCAGGGGAGAAGAATGCAC & $\begin{array}{l}\text { GGGTCTTGATGAGGTGAG } \\
\text { GG }\end{array}$ & 250 & $(\mathrm{ACAA})_{6}$ & 4 & 0.109 & 0.114 & 0.110 & ND & MT737295 \\
\hline Av33 & CCAAACCACACAGCTCAACG & $\begin{array}{l}\text { CCAAACCACACAGCTCAA } \\
\text { CG }\end{array}$ & 180 & $(\mathrm{AT})_{9}$ & 3 & 0.337 & 0.339 & 0.312 & ND & MT737296 \\
\hline $\operatorname{Av} 39$ & CGCTTGCTGCCTCATCATTC & $\begin{array}{l}\text { CCCTCTCACACCATCCCA } \\
\text { AC }\end{array}$ & 271 & $(\mathrm{TGC})_{6}$ & 3 & 0.545 & 0.651 & 0.575 & NS & MT737297 \\
\hline Av43 & CTGCATTCCCGCAAGTAACAG & $\begin{array}{l}\text { TGATGCAGCTTAGGAGGG } \\
\text { TC }\end{array}$ & 258 & $(\mathrm{AAG})_{5}$ & 2 & 0.356 & 0.294 & 0.250 & ND & MT737298 \\
\hline Av55 & GCTCCGAGAAATCCTGCTCA & GCACTGCACCCTCCTACTAC & 218 & $(A G)_{9}$ & 3 & 0.030 & 0.030 & 0.029 & ND & MT737299 \\
\hline Av63 & GGGTTTGCTTCTGGGCATG & GAGCCAATCCGAACCCCAC & 157 & $(\mathrm{TC})_{9}$ & 2 & 0.327 & 0.301 & 0.254 & ND & MT737300 \\
\hline$A \vee 75$ & TCACTAGTACCCACCACCCC & $\begin{array}{l}\text { AGTGGTGGCGTTGCTA } \\
\text { TGAA }\end{array}$ & 212 & $(\mathrm{GT})_{6}(\mathrm{AT})_{6}$ & 2 & 0.485 & 0.490 & 0.369 & NS & MT737301 \\
\hline Av88 & $\begin{array}{l}\text { TGCATCATGTAGGGTACA } \\
\text { CACC }\end{array}$ & GCAAGTGTTCGCTGAGTTCC & 159 & $(\mathrm{AAT})_{7}$ & 4 & 0.396 & 0.487 & 0.400 & NS & MT737302 \\
\hline Mean & & & & & 3.25 & 0.336 & 0.342 & 0.297 & & \\
\hline
\end{tabular}

Notes: $N_{\mathrm{A}}$ number of alleles, $H_{O}$ observed heterozygosity, $H_{\mathrm{E}}$ expected heterozygosity, PIC polymorphism information content, $H W E$ Hardy-Weinberg equilibrium, NS Not significant for departure from HWE, ND Not detected for departure from HWE

suggesting a decrease in gene flow over the last few generations. The Mantel test for isolation by distance did not detect a significant correlation between genetic and geographical distance $(\mathrm{r}=0.164, \quad P=0.251) \quad$ (Additional file 4: Fig. S3).

\section{Changes of effective population size}

Under both the stepwise mutation model (SMM) and two-phase mutation model (TPM), our Wilcoxon test detected no significant heterozygote excess for most of the populations (Table 6). For the $\mathrm{BH}$ population, we detected an evidence of a historical bottleneck $(P<0.05$; Table 6). Likewise, the mode-shift test revealed that most populations showed an L-shaped distribution of alleles, suggesting the absence of a recent bottleneck. The observation of a shifted mode in the two populations (QG, BH) suggested the occurrence of bottleneck events over the last few generations (Table 6).

Table 4 Geographic information and genetic characteristics of A. venetum populations based on 12 EST-SSR markers in the Yancheng coastal habitats of Jiangsu Province

\begin{tabular}{|c|c|c|c|c|c|c|c|c|c|c|}
\hline Population ID & Location & Latitude $\left({ }^{\circ} \mathrm{N}\right)$ & Longitude $\left({ }^{\circ} \mathrm{E}\right)$ & Altitude (m) & Sample size & $N_{A}$ & $H_{\circ}$ & $H_{\mathrm{E}}$ & $A R$ & $F_{I S}$ \\
\hline$\overline{\mathrm{QG}}$ & Qianggang & 32.764 & 120.931 & 4.4 & 14 & 2.25 & 0.369 & 0.332 & 2.19 & -0.075 \\
\hline LD & Liangduo & 32.874 & 120.912 & 9.0 & 24 & 2.25 & 0.303 & 0.293 & 2.09 & -0.012 \\
\hline DF & Dafeng & 32.952 & 120.898 & -2.5 & 18 & 2.17 & 0.361 & 0.310 & 2.06 & -0.138 \\
\hline$X Y$ & Xinyang & 33.690 & 120.287 & -8.0 & 13 & 2.58 & 0.410 & 0.363 & 2.52 & -0.090 \\
\hline SY & Sheyang & 33.877 & 120.432 & -2.2 & 24 & 2.25 & 0.264 & 0.244 & 1.96 & -0.061 \\
\hline $\mathrm{BH}$ & Binghai & 34.008 & 119.789 & -0.5 & 10 & 2.00 & 0.392 & 0.340 & 2.00 & -0.102 \\
\hline Mean & & & & & & 2.25 & 0.350 & 0.314 & 2.34 & -0.080 \\
\hline
\end{tabular}

Notes: $N_{\mathrm{A}}$ number of alleles; $H_{\mathrm{O}}$ observed heterozygosity, $H_{\mathrm{E}}$ expected heterozygosity, $A R$ allelic richness, $F_{\mathrm{IS}}$ within-population inbreeding coefficient 


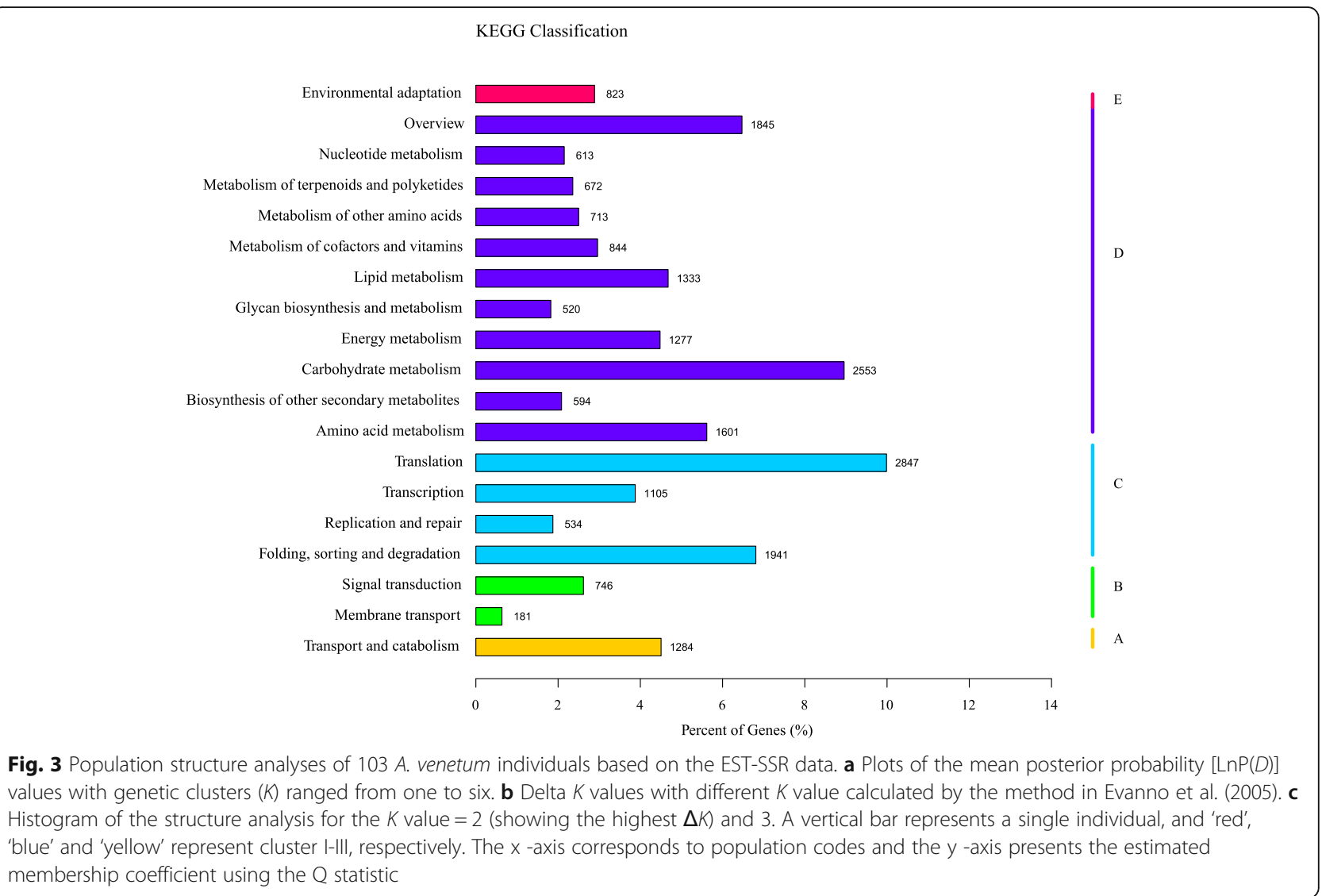

\section{Discussion}

Characterization of $A$. venetum transcriptome and its potential use in germplasm resources evaluation

With the decreasing costs of sequencing, the development of molecular markers that based on nextgeneration sequencing technology has become the most efficient method for molecular studies of non-model plants $[25,26]$. Using the Illumina sequencing platform, we acquired a well-assembled transcriptome sequencing data and developed a set of novel EST-SSR markers for A. venetum. As an important medicinal species and source of fiber, $A$. venetum has been the subject of

Table 5 Pairwise $F_{\text {ST }}$ values among the six populations of $A$. venetum

\begin{tabular}{lllllll}
\hline & QG & LD & DF & XY & SY & BH \\
\hline QG & 0.000 & & & & & \\
LD & 0.032 & 0.000 & & & & \\
DF & $\mathbf{0 . 0 8 2}$ & $\mathbf{0 . 0 6 8}$ & 0.000 & & & \\
XY & $\mathbf{0 . 0 8 4}$ & $\mathbf{0 . 0 5 9}$ & $\mathbf{0 . 0 6 4}$ & 0.000 & & \\
SY & $\mathbf{0 . 1 2 3}$ & $\mathbf{0 . 0 9 4}$ & $\mathbf{0 . 2 2 0}$ & $\mathbf{0 . 1 8 1}$ & 0.000 & \\
BH & $\mathbf{0 . 0 9 9}$ & $\mathbf{0 . 0 8 5}$ & 0.061 & $\mathbf{0 . 1 0 0}$ & $\mathbf{0 . 1 7 1}$ & 0.000
\end{tabular}

Note: Values in bold were significantly different from zero after sequential Bonferroni correction. extensive genetics and pharmacology studies. So far, ISSR (Inter-Simple Sequence Repeat), AFLP and RAPD molecular markers have been developed for A. venetum $[23,24,27]$. In recent years, a number of transcriptome analyses have been conducted on A. venetum [20-22]. Using leaf material, we acquired a similar amount of

Table 6 Bottleneck analysis for six populations of A. venetum. Pvalues are shown for Wilcoxon's sign-rank test under both the stepwise mutation model (SMM) and the two-phase mutation model (TPM), along with the shape of the allelic distribution inferred from the mode-shift test

\begin{tabular}{|c|c|c|c|}
\hline \multirow[t]{2}{*}{ Population } & \multicolumn{2}{|c|}{ Wilcoxon's sign-rank test } & \multirow{2}{*}{$\begin{array}{l}\text { Mode-shift } \\
\text { test } \\
\text { (distribution } \\
\text { shape) }^{a}\end{array}$} \\
\hline & TPM & SMM & \\
\hline$\overline{\mathrm{QG}}$ & 0.116 & 0.348 & shifted mode \\
\hline LD & 0.348 & 0.688 & L-shaped \\
\hline DF & 0.102 & 0.326 & L-shaped \\
\hline$X Y$ & 0.483 & 0.711 & L-shaped \\
\hline SY & 0.688 & 0.839 & L-shaped \\
\hline $\mathrm{BH}$ & 0.007 & 0.007 & shifted mode \\
\hline
\end{tabular}

${ }^{a}$ Note that an L-shaped distribution of alleles is expected in the absence of a bottleneck, whereas a distribution with a shifted mode is expected in a population that has gone through a bottleneck 
transcriptome data $(6.96 \mathrm{~Gb})$ to that obtained by Chen et al. [20] $(6.57 \mathrm{~Gb})$ but greater numbers of unigenes $(86,890$ vs. 52,983$)$ and SSRs $(14,072$ vs. 7579$)$. Li et al. [22] identified 101,918 SSRs in the whole genome of $A$. venetum. Their study indicated that AT/TA and AAT/ TTA accounted for the highest proportions of dinucleotide and trinucleotide repeats, respectively. In our study, we found that AG/CT (34.50\%) was the most frequent motif among the dinucleotide repeats and that AAG/ CTT $(8.99 \%)$ was the most common trinucleotide repeat. In the study of EST-SSRs in 55 dicotyledonous species, Kumpatla and Mukhopadhyay [28] found that AG/GA/ CT/TC (14.6 to $54.5 \%$ of the total SSRs observed in a species), and AAG/AGA/GAA/CTT/TTC/TCT (2.7 to $15.5 \%)$ were the predominant di- and trinucleotide SSRs. The consistent composition of EST-SSR repeats compared with most other plant species and the differences in nuclear SSRs found in A. venetum might suggest a transcriptional preference and conservative function of these SSR motifs in plant genomes. For instance, studies have shown that CT microsatellites in $5^{\prime}$ UTRs play a role in gene regulation and are involved in antisense transcription and that CTT repeats occur in $5^{\prime}$ UTRs and transcribed regions at a high frequency $[29,30]$. $A$. venetum is widely distributed from the northwest region to the coast of the Yellow Sea in China; however, the genetic studies of $A$. venetum published to date have only focused on the arid northwest region of China. Our transcriptome data enriched the available genetic information for $A$. venetum from subhumid region and will facilitate the screening of germplasm resources, especially in coastal regions.

$A$. venetum has been used to lower blood pressure and lipemia as a traditional medicine for a long time in China, and the roasted leaves of $A$. venetum have been commercialized as a sedative and anti-ageing supplement. A. venetum is rich in flavonoid compounds, which provide its broad pharmacological activities [31, 32]. Flavonoids are synthesized through a long, complex pathway [33]. Identifying the regulatory mechanisms underlying flavonoid biosynthesis is essential for understanding the chemical composition or pharmacological activities of Apocynum. Previous studies have shown that $A$. venetum has a higher flavonoid content than its related species Apocynum. hendersonii, and some flavonoid components such as hyperoside have been identified as suitable chemical markers for the discrimination of the two species [34]. In a recent metabolome and transcriptome analyses of Apocynum, Gao et al. [21] found that the flavonoid biosynthetic pathway is responsible for a considerable proportion of the diversity between $A$. venetum and $A$. hendersonii, and identified anthocyanin as the key component that determines the phenotypic diversity of the stem and leaf color of $A$. venetum and $A$. hendersonii. In our KEGG analysis, 28,505 unigenes were clustered into 130 pathways, including the flavone and flavonol biosynthesis (ko00944), flavonoid biosynthesis (ko00941), isoflavonoid biosynthesis (ko00943), and anthocyanin biosynthesis (ko00942) pathways. Among the 88 unigenes related to these pathways, 84 unigenes have an average FPKM (Fragments per kilobase of exon per million fragments mapped) value greater than one and 24 of these were above 50 . In addition, 23 out of these 88 unigenes contain SSR loci (Additional file 5: Table S2). For example, unigenes that annotated as flavonol synthase (NR ID: BAD34463.1) and flavonoid 3O-galactosyltransferase (NR ID: BAF49284.1), both contained SSRs and exhibited an average FPKM value of 50.38 and 22.16, respectively. Although ITS and cpDNA sequences have been used to identify $A$. venetum and its related species, these sequences are conservative within the genus and only provide limited genetic information [35]. The flavonoid biosynthesis related transcripts that contain SSRs identified in our study will serve as good candidates for the development of novel molecular markers in the future, which might aid in both the species identification in the Apocynum genus and the selection of $A$. venetum germplasm resources with high bast fiber and flavonoid content.

\section{Low level of genetic diversity in $A$. venetum coastal populations}

The disturbance of natural habitats poses a major threat to global biodiversity [36]. The ongoing process of habitat alteration generally has strong negative impacts on the species composition and genetic diversity of species [37-39]. The genetic evaluation of natural populations is an essential step in the conservation and utilization of plant resources, especially for vulnerable and threatened species. Using RAPD and AFLP markers, researchers have detected moderate to high levels of genetic diversity in natural $A$. venetum populations from the Xinjiang and Inner Mongolia regions [23, 24]. They have also found that the genetic diversity of A. venetum is significantly correlated with environmental factors such as precipitation, elevation and latitude. Based on EST-SSR markers, we detected a low level of genetic diversity in natural $A$. venetum populations from the coastal habitats $\left(H_{\mathrm{e}}=0.342\right)$ (Table 4). Although EST-SSRs are expected to be more conserved and exhibit a lower rate of polymorphism than genomic SSRs [40-43], there are also studies showing that there is no significant differences between these two types of markers [44-46]. Considering the small population size of the A. venetum populations in the coastal region, future studies that combine the analysis of genomic SSR markers or genome-wide SNPs could better represent the real level of genetic diversity in $A$. venetum from this region. 
Coastal plant species are expected to be highly vulnerable to habitat alteration, due to their high specialization to coastal environments [6]. Through nuclear SSR analysis, a low level of genetic diversity has been observed in coastal herb, shrub and tree species [47-49]. Peng et al. [50] investigated the genetic diversity of nine wild $A$. venetum populations from eight provinces of China using RAPD markers, and their study showed that populations from coastal regions such as Jiangsu and Jilin exhibit lower genetic diversity than those from the arid northwest regions such as Xinjiang, Inner Mongolia and Ningxia. In a comparative study of Fraxinus angustifolia Vahl populations from the Continental region and the Mediterranean region, Temunović et al. [51] detected a significantly lower genetic diversity and higher population divergence in the latter region, revealing the influence of environmental heterogeneity in shaping the genetic variation between divergent habitats. Therefore, coastal $A$. venetum populations might represent a divergent ecotype, and environmental factors may cause differences in genetic diversity between arid and subhumid regions. By including environmental data in our future analyses, we could further test whether the differences are correlated with diverse natural conditions (subhumid vs. arid areas). Another plausible explanation for this low level of genetic diversity is that $A$. venetum populations in the coastal region have experienced severe reductions in population size, leading to the loss of genetic diversity and increased susceptibility. Using Bottleneck software, we found that two populations (QG and $\mathrm{BH}$ ) showed distortions (modeshifts) in their allele frequency distributions, suggesting recent bottleneck events, and Wilcoxon's test also revealed significant heterozygote excess in the $\mathrm{BH}$ population $(P<0.05$; Table 6$)$. According to our field observations, for populations such as $\mathrm{BH}$ and SY, situated along the highway road, the natural habitat is severely being disturbed. In addition, the population size of most populations is quite small $(N<30)$. Based on scaled effective population sizes $\Theta\left(4 N_{\mathrm{e}} \mu\right)$, the estimated $N_{\mathrm{e}}$ of the A. venetum populations in the Yancheng region is approximately $10-11$ individuals. According to a genetic model predicting the proportion of initial heterozygosity retained per generation $\left[1-\left(1 / 2 N_{\mathrm{e}}\right)\right][52]$, A. venetum populations would be expected to lose $4.5 \%$ of their heterozygosity per generation. Therefore, with declining genetic diversity and continuing demographic changes over time, the $A$. venetum populations in the Yancheng coastal region are of potential concern in terms of decreases in individual fitness and population viability, and an increased risk of extinction in the future.

\section{Moderate level of gene connection with a decreasing trend in $A$. venetum coastal populations}

Gene flow is crucial for population resilience and persistence following habitat disturbances and environmental changes. This process may provide a source of recruitment and maintain genetic diversity by introducing adaptive alleles from other populations [53-55]. In this study, we found little evidence of strong genetic structuring in the A. venetum populations across the Yancheng coastal region. Genetic structure analysis grouped all of the sampled populations into two clusters, and in the majority of populations, a number of admixed plants existed (Fig. 3c). Negative multilocus $F_{\text {IS }}$ values (mean value of - 0.08 ) were found for A venetum, indicating an absence of inbreeding in the coastal populations of this species (Table 4). In accordance with this, contemporary migration rates among $A$. venetum coastal populations were found to be moderate (mean $m_{\mathrm{c}}=$ 0.056) (Additional file 3: Table S1). Together, these results indicate that population connectivity in A. venetum coastal populations has not yet been greatly disturbed yet. In general, life-history traits of plant species such as their pollen and seed dispersal mode, often affect the genetic connection between populations $[55,56]$. The study of pollination biology has shown that Apis mellifera and Ichneumon sp. are the main pollinators of $A$. venetum [57]. Due to the limited foraging distances of these pollinators, gene dispersal through pollen alone seems insufficient to maintain the species' population connectivity across the coastal region. The seeds of $A$. venetum are less than $1 \mathrm{~mm}$ in size and are covered with pappus-like hair, which enables an anemochorous dispersion $[58,59]$. The high seed dispersal capabilities of $A$. venetum may play a key role in maintaining the moderate levels of ongoing gene flow and population connectivity across the coastal region. Although studies have shown that plants relying on wind for pollination or seed dispersal may be subject to less negative effects of habitat alteration on their genetic diversity or population connection $[55,56]$, we still detected a decrease in gene flow over the last few generations compared to the historical level of migration rates (mean $m_{\mathrm{h}}=0.106$ ). Under the persistent pressures of anthropogenic and climate disturbances, whether natural $A$. venetum populations, especially those with low genetic diversity and a small population size, have a sufficient capacity to survive following disturbance or adapt to future environmental change still requires long-term monitoring.

\section{Conclusion}

In this study, we acquired a high-quality transcriptome from $A$. venetum leaves by using the Illumina sequencing platform and successfully developed twelve polymorphic EST-SSR markers in A. venetum. Using these 
informative makers, we detected a low level of genetic diversity and bottleneck events in A. venetum populations across their natural distribution in the Yancheng coastal region of Jiangsu Province. Although population connectivity between $A$. venetum populations has been maintained by the high seed dispersal ability of the species, considering the ongoing anthropogenic activities, long-term monitoring and conservation strategies should be implemented to better protect these small populations. The conservation of available genetic diversity is essential to enable the continued utilization of this economically important plant. Based on the results of this study, we suggested that populations that have undergone bottlenecks (e.g., population $\mathrm{BH}$ and $\mathrm{QG}$ ) and those with a high level of genetic diversity (population $\mathrm{XY}$ ), should be given conservation priority. In addition, there are not enough comparative data available on the extent of genetic diversity in $A$. venetum across its global biogeographical ranges, and further studies combining samples from arid regions and more markers should be conducted to gain a more precise understanding of the genetic diversity, population structure, and evolutionary history of this important plant species.

\section{Methods}

\section{Sample collection and DNA and RNA extraction}

A total of 103 leaf samples of $A$. venetum were collected from 10 to 24 individuals in six wild populations, representing most of the distribution area of this species in Jiangsu Province (Fig. 4). Detailed information for all the populations is listed in Table 4. A. venetum is mainly distributed along the riversides or roadsides, and permission was not necessary to collect these samples. The collection of plant material complied with national guidelines. All sampled leaves were immediately dried in silica gel. The materials were identified by Jiangsu Province and Chinese Academy of Sciences, China. We used QIAGEN Plant DNA kit (Gaithersburg, MD) to extract

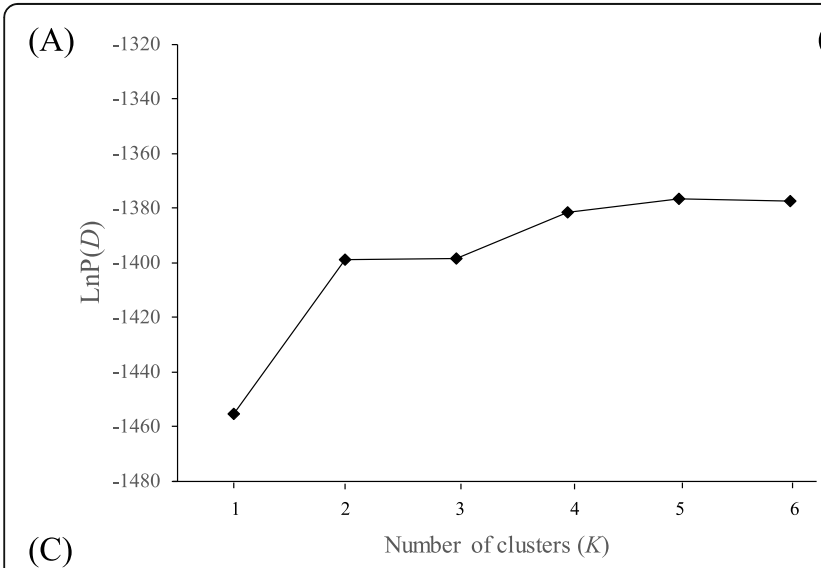

(B)

(C)


Fig. 4 Sample localities of Apocynum venetum in the Yancheng coastal habitats of Jiangsu Province. Population code is listed in Table 4 
the total genomic DNA according to the manufacturer's protocol. Besides, fresh leaves of three individuals from the LD population were immediately frozen in liquid nitrogen and stored at $-70^{\circ} \mathrm{C}$ for total RNA extraction. Total RNA from these individuals was extracted using the QIAGEN RNeasy Plant Mini Kit following the manufacturer's procedures (Chatsworth, CA). Then the quantified total RNAs were sent to Novogene Bioinformatics Institute (Beijing, China) for further processing.

\section{cDNA library construction and transcriptome sequencing}

First, the RNA concentration and integrity of the samples were measured using the Qubit RNA Assay Kit in a Qubit 2.0 Fluorometer (Life Technologies, Carlsbad, CA, USA) and the RNA Nano 6000 Assay Kit with the Agilent Bioanalyzer 2100 system (Agilent Technologies, Santa Clara, CA, USA). Then, for each sample, cDNA library were construction and sequenced by using equal amounts of qualified RNA according to the standard procedures of Novogene Bioinformatics Institute (Beijing, China). The NEBNext $^{\circ}$ Ultra $^{\text {Tx }}$ RNA Library Prep Kit for Illumina ${ }^{\circ}$ (NEB, USA) were used to generate sequencing libraries. After purification and quality assessment, the three library preparations were sequenced on the Illumina HiSeq platform (Illumina, USA).

\section{Transcriptome assembly and functional annotation}

Raw RNA-seq reads were processed using in-house Perl scripts to remove reads containing adapters and ploy- $\mathrm{N}$ sequences (greater than $5 \%$ ) and reads with more than $20 \%$ low-quality bases (quality scores $<10$ ). Then, we used Trinity software [60] with the default parameters to assemble the high-quality clean data. All unigenes were queried against the NCBI Nr (non-redundant protein) and Nt (non-redundant nucleotide) databases; the SwissProt protein database (http://www.expasy.ch/sprot); Pfam (Protein family database); the KOG (Clusters of Orthologous Groups of proteins) database and $\mathrm{KO}$ (KEGG Orthology) database. Gene ontology (GO) annotation [61] of the unigenes was performed using BLAST2go [62]. The Kyoto Encyclopedia of Genes and Genomes (KEGG) pathways (https://www.genome.jp/ $\mathrm{kegg} /$ ) were determined with an E-value cut-off of 1e-5. The WEGO [63] were used to plot the distributions of level-2 GO terms with functional classification.

\section{Identification of EST-SSRs}

The MicroSAtellite (MISA) program [64] was used to detect transcripts containing EST-SSRs. A minimum repeat number of six for dinucleotide motifs and five for tri-, tetra-, penta-, and hexanucleotide motifs were set as detection criteria. The sequences containing SSRs were submitted to Primer premier 5.0 software (Premier Biosoft International, Palo Alto, CA, USA) to design primers. The parameter settings were as follows: product size ranging from 100 to $300 \mathrm{bp}$; primer length ranging from 18 to $25 \mathrm{bp}$; GC content between 40 and $60 \%$ and the annealing temperature between 55 and $65^{\circ} \mathrm{C}$ [65].

PCR amplification was carried out in a $15 \mu \mathrm{L}$ total reaction volume containing 20-40 ng genomic DNA, $7.5 \mu \mathrm{l}$ of $2 \times$ Taq PCR MasterMix (Tiangen, Beijing, China) and $0.3 \mu \mathrm{M}$ of each primer. The PCR procedure included an initial denaturation for $3 \mathrm{~min}$ at $94{ }^{\circ} \mathrm{C}$, followed by $35 \mathrm{cy}$ cles of $30 \mathrm{~s}$ at $94{ }^{\circ} \mathrm{C}, 30 \mathrm{~s}$ at optimal annealing temperature for each locus, and $15 \mathrm{~s}$ at $72{ }^{\circ} \mathrm{C}$, followed by a final extension of $5 \mathrm{~min}$ at $72{ }^{\circ} \mathrm{C}$. The PCR products were checked using silver-stained nondenaturing polyacrylamide gels. Then the optimized SSR primers were further labelled with 6-FAM or HEX fluorescein dye (Sangon Biotech, Shanghai, China). After PCR amplification, allele identification and genotyping were performed with GeneMarker version 2.2.0 (SoftGenetics, State College, Pennsylvania, USA).

\section{Genetic diversity analyses}

The number of alleles $\left(N_{\mathrm{A}}\right)$, polymorphism information content (PIC), expected heterozygosity $\left(H_{\mathrm{E}}\right)$ and observed heterozygosity $\left(H_{\mathrm{O}}\right)$ of each EST-SSR locus were estimated with CERvUS 2.0 [66]. Hardy-Weinberg equilibrium (HWE) and linkage disequilibrium (LD) tests were performed using GENEPOP version 4.2 with a Bonferroni correction [67]. Null allele frequencies, stuttering, and large allele dropout were detected using the MicroCHECKER version 2.2.3 [68] program. For each population of $A$. venetum, the number of alleles $\left(N_{\mathrm{A}}\right)$, allelic richness (AR), expected heterozygosity $\left(H_{\mathrm{E}}\right)$, observed heterozygosity $\left(H_{\mathrm{O}}\right)$, inbreeding coefficient $\left(F_{\mathrm{IS}}\right)$ and differentiation among populations $\left(F_{\mathrm{ST}}\right)$ were calculated using Fstat version 2.9.3.2 [69].

\section{Population genetic structure, gene flow and demographic analyses}

Population structure was investigated by using the SRUCTURE 2.3.4 program [70] implementing a model based Bayesian approach. The value of genetic clusters $(K)$ was set from 1 to 6 , assuming an admixture model and independent allele frequencies. Ten independent runs were conducted for each $K$ with a burn-in of 10,000 and 100, 000 Markov Chain Monte Carlo replicates. The most possible $K$ value was chosen by calculating $\Delta K$ [71] in Structure Harvester [72].

Contemporary inter-population migration between $A$. venetum populations was estimated using BAYESAss version 1.3 [73]. The delta values for allele frequencies, migration rates, and inbreeding coefficients were adjusted accordingly to ensure that the acceptance rates fell between 40 and $60 \%$ [73]. We performed the software for $10^{7}$ iterations with a burn-in of $10^{6}$ generations. Ten 
replicate runs were conducted with a different initial seed. We assessed the model convergence by comparing the posterior probability densities of parameter estimates across these ten runs. The results presented were from the best-fit run. We also estimated historical gene flow using a coalescent-based Bayesian method implemented in the program MigRaTE-N version 3.6 [74]. The process used the Brownian motion approximation as the mutation model following $10^{7}$ iterations with a burn-in of $10^{5}$. The static heating scheme was used with four chains at different temperatures (1.0, 1.5, 3.0, and 100, 000.0) [75]. Two parameters, scaled effective population sizes $\Theta\left(4 N_{\mathrm{e}} \mu\right.$, where $N_{\mathrm{e}}$ is effective population size, $\mu$ is the average mutation rate of microsatellites as $10^{-3}$ per generation) and scaled immigration rates $\mathrm{M}\left(m_{\mathrm{h}} / \mu\right.$, where $m_{\mathrm{h}}$ is historical migration rate) between pairs of populations over around $4 N_{\mathrm{e}}$ generations were estimated simultaneously. The number of immigrants per generation $\mathrm{Nm}$ was estimated by the equation $\mathrm{Nm}=\Theta \mathrm{M} / 4$. A Wilcoxon signed-rank test was conducted to compare historical and contemporary gene flow estimates among the $A$. venetum populations.

To test for isolation-by-distance (IBD), the correlation of pairwise geographical distance (log geographical distance in $\mathrm{km})$ and genetic distance $\left(F_{\mathrm{ST}} / 1-F_{\mathrm{ST}}\right)$ values was evaluated. Statistical significance was tested with 1000 permutations of the Mantel test via the $R$ package Vegan [76]. Wilcoxon's signed rank test and the mode-shift test in BOTTLENECK version 1.2.02 [77] were used to determine whether the A. venetum populations in the Yancheng coastal region have undergone significant reductions in the effective population size $\left(N_{\mathrm{e}}\right)$. The first methodology compares the heterozygosity expected $\left(H_{\mathrm{E}}\right)$ at Hardy-Weinberg equilibrium with the heterozygosity expected at mutation-drift equilibrium $\left(H_{\mathrm{eq}}\right)$ [78], which is suitable for detecting bottlenecks occurring in the last $2-4 N_{\mathrm{e}}$ generations. The second methodology is based on the allele frequency distribution, which is more appropriate for detecting population declines that have occurred more recently (approximately the last few dozen generations) $[79,80]$. For population that has not experienced bottleneck event, a large proportion of alleles at a low frequency and a smaller proportion of alleles at intermediate frequencies distribution (L-shape distribution) presents. While in bottlenecked populations, a shifted mode of allele frequency distribution would be detected. We performed 10,000 simulations under both the stepwise mutation model (SMM) and the two-phase model (TPM) with 95\% single-step mutations and 5\% multistep mutations for each A. venetum population. $P$-values were assessed for statistical significance at the 0.05 level.

\section{Supplementary information}

Supplementary information accompanies this paper at https://doi.org/10. 1186/s12870-020-02626-7.

Additional file 1: Fig. S1. Length distribution of assembled unigenes (A) and the number of reads mapped to each unigene (B) that generated from $A$. venetum transcriptome.

Additional file 2: Fig. S2. KOG classification of assembled unigenes of A. venetum.

Additional file 3: Table S1. MIGRATE-N results of historical gene flow and BAYESASS results of contemporary gene flow with 95\% confidence among the Apocynum venetum populations.

Additional file 4: Fig. S3. Correlation between genetic differentiation and log geographical distance for the $A$. venetum populations in Jiangsu Province.

Additional file 5 Table S2 The SSR type, expression level and KEGG annotation of 88 flavonoid biosynthesis related genes in $A$. venetum.

\begin{abstract}
Abbreviations
AR: Allelic richness; EST-SSR: Expressed sequence tag-derived simple sequence repeat markers; $F_{\mathrm{IS}}$ : Inbreeding coefficient; $F_{\mathrm{ST}}$ : Differentiation among populations; GO: Gene ontology; $H_{\mathrm{E}}$ : The expected heterozygosity;

$H_{\mathrm{O}}$ : Observed heterozygosity; HWE: Hardy-Weinberg equilibrium; KO: KEGG Ortholog database; KOG: Clusters of Orthologous Groups of proteins; $N_{e}$ : Effective population size; Nr: NCBI non-redundant protein database; Nt: NCBI non-redundant nucleotide database; Pfam: Protein family database
\end{abstract}

\section{Acknowledgements}

We gratefully acknowledge helpful comments made by three anonymous reviewers on a previous version of this article.

\section{Authors' contributions}

NY, ML, CJ conceived and designed the research, and NY performed the research, analyzed the data and wrote the paper. All authors read and approved the manuscript.

\section{Funding}

This work was supported by Chinese National Natural Science Foundation (No. 31800312). The funding agency had no role in the design of the study and collection, analysis and interpretation of data or in writing the manuscript.

\section{Availability of data and materials}

Raw sequencing data used for EST-SSR marker development are available in NCBI SRA: PRJNA614557 (https://www.ncbi.nlm.nih.gov/sra/PRJNA614557). Other datasets supporting the conclusions of this article are included within the article and its additional files.

Ethics approval and consent to participate

Not applicable.

Consent for publication

Not applicable.

\section{Competing interests}

The authors declare that they have no competing interests.

\section{Author details}

${ }^{1}$ Institute of Crop Germplasm and Biotechnology, Provincial Key Laboratory of Agrobiology, Jiangsu Academy of Agricultural Sciences, Nanjing, China ${ }^{2}$ Institute of Botany, Jiangsu Province and Chinese Academy of Sciences, Nanjing, China. ${ }^{3}$ Institute of Agricultural and Sustainable Development, Shandong Academy of Agricultural Sciences, Jinan, China. 
Received: 31 March 2020 Accepted: 27 August 2020

\section{Published online: 03 September 2020}

\section{References}

1. Van Der Maarel E. Some remarks on the functions of European coastal ecosystems. Phytocoenologia. 2003;33:187-202 Available from: https://www. schweizerbart.de/papers/phyto/detail/33/61456.

2. Medail F, Quezel P. Hot-spots analysis for conservation of plant biodiversity in the Mediterranean Basin. Ann Mo Bot Gard. 1997;84:112-27 Available from: https://www.jstor.org/stable/2399957.

3. Bulleri F, Chapman MG. The introduction of coastal infrastructure as a driver of change in marine environments. J Appl Ecol. 2010;47:26-35 Available from: https://besjournals.onlinelibrary.wiley.com/doi/full/10.1111/ j.1365-2664.2009.01751.x.

4. Baastrup-Spohr L, Sand-Jensen K, Nicolajsen SV, et al. From soaking wet to bone dry: predicting plant community composition along a steep hydrological gradient. J Veg Sci. 2015;26:619-30 Available from: https:// onlinelibrary.wiley.com/doi/full/10.1111/jvs.12280.

5. Stefanaki A, Kantsa A, Tscheulin T, et al. Lessons from red data books: plant vulnerability increases with floral complexity. PLoS One. 2015;10:e0138414 Available from: https://www.ncbi.nlm.nih.gov/pmc/articles/PMC4577097/.

6. Doxa A, Albert $\mathrm{CH}$, Leriche $\mathrm{A}$, et al. Prioritizing conservation areas for coastal plant diversity under increasing urbanization. J Environ Manag. 2017;201: 425-34 Available from: https://www.sciencedirect.com/science/article/pii/ S0301479717306023.

7. Chen $\mathrm{HQ}$, Zhang HB. Ecological restoration in Yancheng coastal wetlands (in Chinese with English abstract). Trans Oceanol Limnol. 2016;4:43-9 Available from: http://www.wanfangdata.com.cn/details/detail.do?_type= perio\&id=hyhztb201604007.

8. Zhu Y, Kong L, Zhang X, Wang QY. Research on flora and plant resources on beach wetland of Yancheng Jiangsu (in Chinese with English abstract). J Biol. 2014;5:71-5 Available from: http://www.wanfangdata.com.cn/details/ detail.do?_type=perio\&id=swxzz201405016.

9. Baur B, Erhardt A. Habitat fragmentation and habitat alterations: principal threats to most animal and plant species. GAIA. 1995:4:221-6 Avaeilable from: https://www.ingentaconnect.com/content/oekom/gaia/1995/ 00000004/00000004/art00005.

10. Lande R. Anthropogenic, ecological and genetic factors in extinction and conservation. Popul Ecol. 1998;40:259-69 Available from: https://esj-journals. onlinelibrary.wiley.com/doi/abs/10.1007/BF02763457.

11. Frankham R. Genetics and extinction. Biol Conserv. 2005;126:131-40 Available from: https://www.sciencedirect.com/science/article/pii/S000632 0705002089

12. Boivin NL, Zeder MA, Fuller DQ, et al. Ecological consequences of human niche construction: examining long-term anthropogenic shaping of global species distributions. Proc Natl Acad Sci U S A. 2016;113:6388-96 Available from: https://www.pnas.org/content/113/23/6388.full.

13. Thompson TQ, Bellinger MR, O'Rourke SM, et al. Anthropogenic habitat alteration leads to rapid loss of adaptive variation and restoration potential in wild salmon populations. Proc Natl Acad Sci U S A. 2019;116:177-86 Available from: https://www.pnas.org/content/116/1/177.full.

14. Dong ZJ. A new advanced textile fiber plant in China-Apocynum (in Chinese with English abstract). Chin Sci Bull. 1957;19:607-8 Available from: http://csb. scichina.com:8080/CN/abstract/abstract349910.shtml.

15. Zhang YX, Li GQ, Zhang Q, Zhang H, Zhu L, Wan HX. The preliminary research on photosynthetic characteristics of Apocynum venetum under different shading (in Chinese with English abstract). Acta Botan BorealiOcciden Sin. 2007;27:2555-8 Available from: http://en.cnki.com.cn/Article_ en/CJFDTotal-DNYX200712034.htm.

16. Wang DQ, Li GQ, Wang L. Daily dynamics of photosynthesis and water physiological characteristics of Apocynum venetum and Apocynum cannabinum under drought stress (in Chinese with English abstract). Acta Botan Boreali-Occiden Sin. 2012;32:1198-205 Available from: https://www. cabdirect.org/cabdirect/abstract/20123262378.

17. Li XT, Wu T, Yu ZH, et al. Apocynum venetum leaf extract reverses depressive-like behaviors in chronically stressed rats by inhibiting oxidative stress and apoptosis. Biomed Pharmacother. 2018;100:394-406 Available from: https://doi:10.1016/j.biopha.2018.01.137.

18. Buschiazzo E, Gemmell NJ. The rise, fall and renaissance of microsatellites in eukaryotic genomes. Bioessays. 2006;28:1040-50 Available from: https:// onlinelibrary.wiley.com/doi/abs/10.1002/bies.20470.
19. Taheri S, Lee Abdullah T, Yusop MR, et al. Mining and development of nove SSR markers using next generation sequencing (NGS) data in plants. Molecules. 2018;23:399 Available from: https://www.mdpi.com/1420-304 9/23/2/399.

20. Chen P, Gao G, Yu C, et al. Data set for transcriptome analysis of Apocynum venetum L. Data Brief. 2018;20:1739-44 Available from: https://www. sciencedirect.com/science/article/pii/S2352340918310679.

21. Gao G, Chen P, Chen J, et al. Genomic survey, transcriptome, and metabolome analysis of Apocynum venetum and Apocynum hendersonii to reveal major flavonoid biosynthesis pathways. Metabolites. 2019;9:296 Available from: https://www.mdpi.com/2218-1989/9/12/296/.

22. Li G, Song L, Jin C, et al. Genome survey and SSR analysis of Apocynum venetum. Biosci Rep. 2019;39:BSR20190146 Available from: https:// portlandpress.com/bioscirep/article/39/6/BSR20190146/219225/.

23. Liu Z, Ma L, Yu Z, et al. AFLP analysis on genetic diversity of Apocynum. Acta Agriculturae Boreali-Sinica. 2009;24:84-9 Available from: http://www. hbnxb.net/EN/10.7668/hbnxb.2009.02.018.

24. Su Q, Qiu L. Study on the genetic diversity of Apocynum in Xinjiang based on RAPD technique. J Agric Catastrophol. 2015;7:1 Available from: http://dx. doi.org/10.19383/j.cnki.nyzhyj.2015.07.001.

25. Ward JA, Ponnala L, Weber CA. Strategies for transcriptome analysis in nonmodel plants. Am J Bot. 2012;99:267-76 Available from: https://bsapubs. onlinelibrary.wiley.com/doi/full/10.3732/ajb.1100334.

26. Strickler SR, Bombarely A, Mueller LA. Designing a transcriptome nextgeneration sequencing project for a nonmodel plant species. Am J Bot. 2012;99:257-66 Available from: https://bsapubs.onlinelibrary.wiley.com/doi/ full/10.3732/ajb.1100292.

27. Liu Z, Yu Z, Dong P, et al. Genetic diversity of Apocynum venetum based on ISSR. Chin J Grassland. 2009;31:96-101 Available from: http://www.cqvip. com/QK/94283A/200905/31593383.html.

28. Kumpatla SP, Mukhopadhyay S. Mining and survey of simple sequence repeats in expressed sequence tags of dicotyledonous species. Genome. 2005:48:985-98 Available from: https://www.nrcresearchpress.com/doi/pdf/1 0.1139/g05-060

29. Morgante M, Hanafey M, Powell W. Microsatellites are preferentially associated with nonrepetitive DNA in plant genomes. Nat Genet. 2002;30: 194-200 Available from: https://www.nature.com/articles/ng822z.

30. Martienssen RA, Colot V. DNA methylation and epigenetic inheritance in plants and filamentous fungi. Science. 2001;293:1070-4 Available from: https://science.sciencemag.org/content/293/5532/1070/tab-pdf.

31. Zhang D, Wang L, Yang Z. Nature products and cardiovascular disorders. In: Rahman A, Choudhary M, editors. Frontiers in cardiovascular drug discovery. Sharjah: Bentham Science Publishers; 2015. p. 3-91.

32. Xie $W$, Zhang $X$, Wang $T$, et al. Botany, traditional uses, phytochemistry and pharmacology of Apocynum venetum L.(Luobuma): a review. J Ethnopharmacol. 2012;141:1-8 Available from: https://www.sciencedirect. com/science/article/pii/S0378874112000712.

33. Castellarin SD, Pfeiffer A, Sivilotti $P$, et al. Transcriptional regulation of anthocyanin biosynthesis in ripening fruits of grapevine under seasonal water deficit. Plant Cell Environ. 2007;30:1381-99 Available from: https:// onlinelibrary.wiley.com/doi/full/10.1111/j.1365-3040.2007.01716.x.

34. Chan CO, Lau CC, Ng YF, et al. Discrimination between leave of Apocynum venetum and its adulterant, $A$ pictum based on antioxidant assay and chemical profiles combined with multivariate statistical analysis. Antioxidants. 2015;4:359-72 Available from: https://www.mdpi.com/2076-3 921/4/2/359.

35. Peng $X$, Zhang $W$, Wang $M$, et al. Molecular identification of Apoacynum venetum and its confusable species. Bull Bot Res. 2007;27:302-7 Available from: http://bbr.nefu.edu.cn/en/y2007/v27/i3/302.

36. Lindenmayer DB, Fischer J. Habitat fragmentation and landscape change: an ecological and conservation synthesis. Washington, DC: Island Press; 2013.

37. Young A, Boyle T, Brown T. The population genetic consequences of habitat fragmentation for plants. Trends Ecol Evol. 1996;11:413-8 Available from: https://www.cell.com/trends/ecology-evolution/pdf/0169-5347(96 )10045-8.pdf.

38. Lowe AJ, Cavers S, Boshier D, et al. The resilience of forest fragmentation genetics - no longer a paradox —we were just looking in the wrong place. Heredity. 2015;115:97-9 Available from: https://www.nature.com/articles/ hdy201540.

39. Aguilar R, Quesada M, Ashworth L, et al. Genetic consequences of habitat fragmentation in plant populations: susceptible signals in plant traits and 
methodological approaches. Mol Ecol. 2008;17:5177-88 Available from: https://onlinelibrary.wiley.com/doi/full/10.1111/j.1365-294X.2008.03971.x.

40. Cho YG, Ishii T, Temnykh S, et al. Diversity of microsatellites derived from genomic libraries and GenBank sequences in rice (Oryza sativa L.). Theor Appl Genet. 2000;100:713-22 Available from: https://link.springer.com/ article/10.1007\%2Fs001220051343.

41. Gupta PK, Rustgi S, Sharma S, Singh R, Kumar N, Balyan HS. Transferable EST-SSR markers for the study of polymorphism and genetic diversity in bread wheat. Mol Gen Genomics. 2003;270:315-23 Available from: https:// link.springer.com/article/10.1007\%2Fs00438-003-0921-4.

42. Liewlaksaneeyanawin C, Ritland CE, El-Kassaby YA, Ritland K. Single-copy, species-transferable microsatellite markers developed from loblolly pine ESTs. Theor Appl Genet. 2004;109:361-9 Available from: https:/link.springer. com/article/10.1007\%2Fs00122-004-1635-7.

43. Chabane K, Ablett GA, Cordeiro GM, Valkoun J, Henry RJ. EST versus genomic derived microsatellite markers for genotyping wild and cultivated barley. Genet Resour Crop Evol. 2005;52:903-9 Available from: https:/link. springer.com/article/10.1007\%2Fs10722-003-6112-7.

44. Kirigwi FM, Zwonitzer JC, Mian MAR, et al. Microsatellite markers and genetic diversity assessment in Lolium temulentum. Genet Resour Crop Evol. 2008;55:105 Available from: https://link.springer.com/article/10.1007/s10722007-9218-5.

45. Tehrani MS, Mardi M, Sahebi J, et al. Genetic diversity and structure among Iranian tall fescue populations based on genomic-SSR and EST-SSR marker analysis. Plant Syst Evol. 2009;282:57-70 Available from: https://link.springer. com/content/pdf/10.1007/s00606-009-0207-3.pdf.

46. Wen M, Wang H, Xia Z, et al. Development of EST-SSR and genomic-SSR markers to assess genetic diversity in Jatropha Curcas L. BMC Res Notes. 2010;3:42 Available from: https://link.springer.com/article/10.1186/1756-05 00-3-42.

47. Islam MS, Lian C, Kameyama N, et al. Low genetic diversity and limited gene flow in a dominant mangrove tree species (Rhizophora stylosa) at its northern biogeographical limit across the chain of three Sakishima islands of the Japanese archipelago as revealed by chloroplast and nuclear SSR analysis. Plant Syst Evol. 2014;300:1123-36 Available from: https://ink. springer.com/article/10.1007/s00606-013-0950-3.

48. Chen W, Wang Z, Zhao G, et al. Microsatellite and chloroplast DNA analyses reveal no genetic variation in a beach plant Surianana maritima on the Paracel Islands, China. Biochem Syst Ecol. 2016;65:171-5 Available from: https://www.sciencedirect.com/science/article/pii/S0305197816300254.

49. Hirai M, Kubo N, Ohsako T, et al. Genetic diversity of the endangered coastal violet Viola grayi Franchet et Savatier (Violaceae) and its genetic relationship to the species in subsection Rostratae. Conserv Genet. 2012;13: 837-48 Available from: https://link.springer.com/content/pdf/10.1007/s105 92-012-0333-2.pdf

50. Peng $X$, Zhang W, Wang $Y$, et al. Genetic diversity study on wild populations of Apoacynum venetum using RAPD marker. J Nanjing Norm Univ (Natural Science Edition). 2008;31:92-6 Available from: http://en.cnki. com.cn/Article_en/CJFDTOTAL-NJSF200804022.htm.

51. Temunović M, Franjić J, Satovic Z, et al. Environmental heterogeneity explains the genetic structure of continental and Mediterranean populations of Fraxinus angustifolia Vahl. PLoS One. 2012;7:e42764 Available from: https:/journals.plos. org/plosone/article?id=10.1371/journal.pone.0042764.

52. Govindaraj $M$, Vetriventhan $M$, Srinivasan $M$. Importance of genetic diversity assessment in crop plants and its recent advances: an overview of its analytical perspectives. Genet Res Int. 2015;2015:431487 Available from: https://www.hindawi.com/journals/gri/2015/431487/\#B9.

53. Chen XY, Fan XX, Hu XS. Roles of seed and pollen dispersal in natural regeneration of Castanopsis fargesii (Fagaceae): implications for forest management. For Ecol Manag. 2008;256:1 143-50 Available from: https:/Www. sciencedirect.com/science/article/abs/pii/S037811270800501X?via\%3Dihub.

54. Bizoux JP, Daïnou K, Bourland N, et al. Spatial genetic structure in Milicia excelsa (Moraceae) indicates extensive gene dispersal in a low-density windpollinated tropical tree. Mol Ecol. 2009;18:4398-408 Available from: https:// onlinelibrary.wiley.com/doi/epdf/10.1111/j.1365-294X.2009.04365.x.

55. Sork VL, Smouse PE. Genetic analysis of landscape connectivity in tree population. Landsc Ecol. 2006;21:821-36 Available from: https://link.springer. com/article/10.1007/s10980-005-5415-9.

56. Wang R, Compton $\mathrm{S}$, Chen XY. Fragmentation can increase spatial genetic structure without decreasing pollen-mediated gene flow in a wind- pollinated tree. Mol Ecol. 2011;20:4421-32 Available from: https:// onlinelibrary.wiley.com/doi/epdf/10.1111/j.1365-294X.2011.05293.X.

57. Chen M, Zhao X, Zuo X. Comparative reproductive biology of Apocynum venetum $L$. in wild and managed populations in the arid region of NW China. Plant Syst Evol. 2015;301:1735-45 Available from: https://link.springer. com/article/10.1007/s00606-014-1192-8.

58. Zhao YF, Gao JH, Zeng YJ, et al. Study on seed morphological characteristics and viability determination method in Apocynum spp. And Poacynum spp. Pratacultural Science. 2020;37:743-52 Available from: http:// cykx.lzu.edu.cn/article/doi/10.11829/j.issn.1001-0629.2019-0261.

59. Bai L, Luo MB, Chuan LC, et al. Short report on planting techniques of Apocynum venetum. Chin Wild Plant Resour. 2005;24:65-8 Available from: http://www.cqvip.com/Main/Detailaspx?id=20417557.

60. Grabherr MG, Haas BJ, Yassour M, et al. Trinity: reconstructing a full-length transcriptome without a genome from RNA-Seq data. Nat Biotechnol. 2011; 29:644-52 Available from: https://www.ncbi.nlm.nih.gov/pmc/articles/PMC35 71712/pdf/nihms292662.pdf.

61. Ashburner M, Ball CA, Blake JA, et al. Gene ontology: tool for the unification of biology. Nat Genet. 2000;25:25-9 Available from: https:/www.nature. com/articles/ng0500_25.

62. Götz S, García-Gómez JM, Terol J, et al. High-throughput functional annotation and data mining with the Blast $2 \mathrm{GO}$ suite. Nucleic Acids Res. 2008:36:3420-35 Available from: https:/www.ncbi.nlm.nih.gov/pmc/articles/ PMC2425479/pdf/gkn176.pdf.

63. Ye J, Fang $\mathrm{L}$, Zheng $\mathrm{H}$, et al. WEGO: a web tool for plotting $\mathrm{GO}$ annotations Nucleic Acids Res. 2006;34:W293-7 Available from: https://www.ncbi.nlm.nih gov/pmc/articles/PMC1538768/pdf/gkl031.pdf.

64. Thiel T, Michalek W, Varshney RK, Graner A. Exploiting EST databases for the development and characterization of gene-derived SSR-markers in Barley (Hordeum vulgare L.). Theor Appl Genet. 2003;106:411-22 Available from: https://link.springer.com/article/10.1007\%2Fs00122-002-1031-0.

65. Dieffenbach CW, Lowe TM, Dveksler GS. General concepts for PCR primer design. PCR Methods Appl. 1993;3:30-7 Available from: http://citeseerx.ist. psu.edu/viewdoc/download?doi=10.1.1.965.1253\&rep=rep1\&type=pdf.

66. Kalinowski ST, Taper ML, Marshall TC. Revising how the computer program CERVUS accommodates genotyping error increases success in paternity assignment. Mol Ecol. 2007;16:1099-106 Available from: https://onlinelibrary. wiley.com/doi/full/10.1111/j.1365-294X.2007.03089.x.

67. Rousset F. genepop'007: a complete re-implementation of the genepop software for windows and Linux. Mol Ecol Resour. 2008:8:103-6 Available from: https:/onlinelibrary.wiley.com/doi/full/10.1111/j.1471-8286.2007.01931.x.

68. Van Oosterhout C, Hutchinson WF, Wills DPM, et al. MICRO-CHECKER: software for identifying and correcting genotyping errors in microsatellite data. Mol Ecol Notes. 2004;4:535-8 Available from: https://onlinelibrary.wiley. com/doi/full/10.1111/j.1471-8286.2004.00684.X.

69. Goudet J. FSTAT, a program to estimate and test gene diversities and fixation indices, version 2.9.3. 2001. Available from: http://www2.unil.ch/ popgen/softwares/fstat.htm.

70. Pritchard JK, Stephens M, Donnelly P. Inference of population structure using multilocus genotype data. Genetics. 2000;155:945-59 Available from: https://www.genetics.org/content/155/2/945.

71. Evanno G, Regnaut S, Goudet J. Detecting the number of clusters of individuals using the software STRUCTURE: a simulation study. Mol Ecol. 2005;14:2611-20 Available from: https://onlinelibrary.wiley.com/doi/full/1 0.1111/j.1365-294X.2005.02553.x.

72. Earl DA, VonHoldt BM. Structure harvester: a website and program for visualizing STRUCTURE output and implementing the Evanno method. Conserv Genet Resour. 2012;4:359-61 Available from: https://link.springer. com/article/10.1007/s12686-011-9548-7.

73. Wilson GA, Rannala B. Bayesian inference of recent migration rates using multilocus genotypes. Genetics. 2003;163:1177-91 Available from: https:// www.genetics.org/content/163/3/1177.short.

74. Beerli $P$, Felsenstein J. Maximum likelihood estimation of a migration matrix and effective population sizes in $\mathrm{n}$ subpopulations by using a coalescent approach. Proc Natl Acad Sci U S A. 2001;98:4563-8 Available from: https:// www.pnas.org/content/98/8/4563.short.

75. Beerli P. Comparison of Bayesian and maximum-likelihood inference of population genetic parameters. Bioinformatics. 2006;22:341-5 Available from: https://academic.oup.com/bioinformatics/article/22/3/341/220586. 
76. Oksanen J, Blanchet FG, Kindt R, et al. Package 'vegan'. Community ecology package, version, vol. 2; 2013. p. 1-295. Available from: https://cran.ism.ac.jp/ web/packages/vegan/vegan.pdf.

77. Piry S, Luikart G, Cornuet JM. BOTTLENECK: a computer program for detecting recent reductions in the effective population size using allele frequency data. J Hered. 1999;90:502-3 Available from: https://pdfs. semanticscholar.org/2379/f4a16108f1a459107a9ed7d5b8ee83ff2d91.pdf.

78. Cornuet JM, Luikart G. Description and power analysis of two tests for detecting recent population bottlenecks from allele frequency data. Genetics. 1996;144:2001-14 Available from: https://www.genetics.org/ content/144/4/2001.full.

79. Luikart G, Allendorf FW, Cornuet JM, et al. Distortion of allele frequency distributions provides a test for recent population bottlenecks. J Hered. 1998;89:238-47 Available from: https://academic.oup.com/jhered/article/ 89/3/238/2186656

80. Spencer CC, Neigel JE, Leberg PL. Experimental evaluation of the usefulness of microsatellite DNA for detecting bottlenecks. Mol Ecol. 2000;9:1517-28 Available from: https://onlinelibrary.wiley.com/doi/full/10.1046/j.1365-294X.2 000.01031.x.

\section{Publisher's Note}

Springer Nature remains neutral with regard to jurisdictional claims in published maps and institutional affiliations.

Ready to submit your research? Choose BMC and benefit from:

- fast, convenient online submission

- thorough peer review by experienced researchers in your field

- rapid publication on acceptance

- support for research data, including large and complex data types

- gold Open Access which fosters wider collaboration and increased citations

- maximum visibility for your research: over $100 \mathrm{M}$ website views per year

At $\mathrm{BMC}$, research is always in progress.

Learn more biomedcentral.com/submissions 